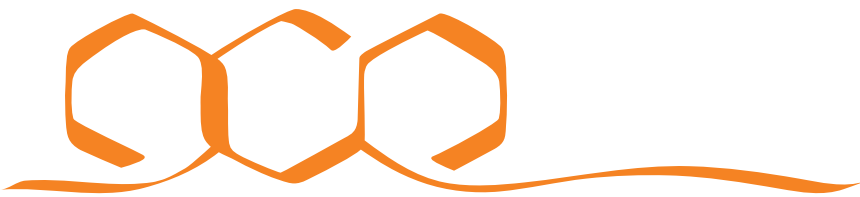 COMMUNICATIONS CHEMISTRY
}

COMMENT

https://doi.org/10.1038/s42004-020-00423-9 OPEN

\section{Main group carbonyl complexes}

\author{
Shiori Fujimori ${ }^{1} \&$ Shigeyoshi Inoue (iD ${ }^{1 凶}$
}

The chemistry of carbon monoxide ( $\mathrm{CO}$ ) as a ligand has evolved significantly and transition-metal carbonyl complexes have been widely used as catalysts in many important catalytic processes. Here the authors comment on the recent progress of main-group element carbonyl complexes along with their future prospects.

Main-group elements belonging to the $s$ - and p-blocks of the periodic table contain some of the most abundant elements in the Earth's crust (e.g., silicon and aluminium) and their compounds are manufactured as commercially valuable chemicals. Main-group chemistry has been studied significantly and various main-group compounds in low-valent oxidation states bearing a highenergy highest occupied molecular orbital and an energetically accessible lowest unoccupied molecular orbital are known to mimic the reactivity of transition-metal (TM) complexes such as the activation of small molecules and catalytic reactions.

Recently, the chemistry of main-group carbonyl complexes has garnered increased attention. Carbon monoxide (CO), a ubiquitous atmospheric trace gas produced by natural and anthropogenic sources, is a versatile feedstock for chemical or material production and is widely utilized in both academia and industry. In organometallic chemistry, $\mathrm{CO}$ is an important ligand (carbonyl) and plays a key role in various catalytic processes. TMs are known to react with CO to form TM carbonyl complexes with various types of TM-CO bonding motifs, e.g., terminal, bridging, and isocarbonyl. The most common TM carbonyl complexes contain terminal $\mathrm{CO}$ bonds, which consists of $\sigma$-donation from CO lone pair to an empty orbital on the TM and $\pi$ backdonation from a filled $d$ orbital of the TM to an empty $\pi^{*}$-orbital on CO. These complexes are used as important reagents in various industrial applications such as hydroformylation, the Cativa process, the Fischer-Tropsch process, and the Pauson-Khand reaction ${ }^{1}$.

\section{Main-group carbonyl complexes}

Although the formation of carbonyl complexes by the simple reaction with $\mathrm{CO}$ is very rare for main-group elements, due to the lack of suitable $\pi$-back-bonding orbitals, some milestone advances in main-group carbonyl chemistry have been recently reported. For the $s$-block elements, only alkaline Earth metal complexes $\mathrm{M}(\mathrm{CO})_{8}(\mathrm{M}=\mathrm{Ca}, \mathrm{Sr}$, or $\mathrm{Ba})$, which are isolated in a low-temperature neon matrix, have been reported by the groups of Zhou, Frenking and colleagues $^{2,3}$. On the other hand, several examples of isolable p-block carbonyl complexes at ambient temperature have been reported. It is known that Lewis acidic boranes such as $\mathrm{BH}_{3}, \mathrm{HB}$ $\left(\mathrm{C}_{6} \mathrm{~F}_{5}\right)_{2}$, and perfluoroalkylboranes react with $\mathrm{CO}$ to form the corresponding boron mono- 
carbonyl complexes, which have a weak CO-B $\sigma$-bonding ${ }^{4}$. Some of the boron mono-carbonyl complexes are known to undergo nucleophilic attack by bases such as $\mathrm{NH}_{3}$ at the carbon atom of the carbonyl. Furthermore, a boron multi-carbonyl complex, the dicarbonyl compound $\mathrm{TpB}(\mathrm{CO})_{2}\left(\mathrm{Tp}=2,6-\left[2,4,6-{ }^{i} \mathrm{Pr}_{3}-\mathrm{C}_{6} \mathrm{H}_{2}\right]_{2}-\right.$ $\mathrm{C}_{6} \mathrm{H}_{3}$ ) (1), was isolated by Braunschweig et al. ${ }^{5}$ (Fig. 1). Compound 1 photolytically liberates CO, similar to TM carbonyl complexes $^{6}$. Besides boron carbonyl complexes, several reactions of phosphorus compounds with $\mathrm{CO}$ have been studied. Grützmacher et al. $^{7}$ have isolated sodium phosphacyanate, $[\mathrm{Na}$ $\left.(\mathrm{O}-\mathrm{C} \equiv \mathrm{P})(\mathrm{dme})_{2}\right]_{2}(2)$, by the reaction of sodium dihydrogen phosphide $\mathrm{NaPH}_{2}$ and $\mathrm{CO}$. In addition, the Bertrand and colleagues ${ }^{8}$ reported the synthesis of the phosphino-phosphaketene $\left(\mathrm{R}_{2} \mathrm{P}-\mathrm{P}=\mathrm{C}=\mathrm{O}\right)(3)$, which can proceed via a ligand exchange reaction at the main-group element center, one of the most prototypical reaction of TM carbonyl complexes.

With regard to Group 14 elements, some studies on the reactivity of stable carbenes (:CR $)$ with $\mathrm{CO}$ have been demonstrated. For instance, the Bertrand and colleagues ${ }^{9}$ revealed that the reaction of stable alkyl(amido)carbenes with $\mathrm{CO}$ afforded the isolable amido ketenes $[\mathrm{C}(\mathrm{N}) \mathrm{C}=\mathrm{C}=\mathrm{O}]$ at ambient temperature. Thus, the reactions of carbenes $\left(: \mathrm{CR}_{2}\right)$ with $\mathrm{CO}$ results in the formal oxidation of carbenes to ketenes $\left(\mathrm{R}_{2} \mathrm{C}=\mathrm{C}=\mathrm{O}\right)$ rather than the formation of Lewis adducts $\left(\mathrm{R}_{2} \mathrm{C} \leftarrow \mathrm{CO}\right)$. In general, reactivity of low-valent main-group compounds towards $\mathrm{CO}$ is dominated by reductive homologation reactions, even without cooperative effects by alkali metals or $\mathrm{TMs}^{10}$. In fact, $\mathrm{CO}$ homologation was observed in the reaction of tetrylene $\left(: \mathrm{ER}_{2}, \mathrm{E}=\mathrm{Si}, \mathrm{Ge}\right)$, the heavier analogs of carbenes $\left(: \mathrm{CR}_{2}\right)$; therefore, the isolation of heavier Group 14 element carbonyl complexes is challenging. Driess and colleagues $^{11}$ reported the reaction of bis-silylenes with $\mathrm{CO}$, which resulted in the selective deoxygenative homocoupling of $\mathrm{CO}$ to form compounds $\mathbf{4 a}$ and $\mathbf{4 b}$. In addition, the reaction of an acyclic amido(boryl)silylene with $\mathrm{CO}$ was demonstrated by Aldridge and colleagues ${ }^{12}$. In this reaction, reductive coupling of $\mathrm{CO}$, followed by insertion reaction into the $\mathrm{Si}-\mathrm{B}$ bond was observed to yield compound $5^{12}$. Furthermore, Power and colleagues ${ }^{13}$ revealed that stable germylenes $\left(: \mathrm{GeR}_{2}\right)$ react with $\mathrm{CO}$ to obtain compound $\mathbf{6}$ via $\mathrm{C}-\mathrm{C}$ bond cleavage and formation.
Very recently, the first synthesis and isolation of a roomtemperature stable carbonyl complex of heavier Group 14 element has been achieved by tuning the substituents on the central element. The groups of Schreiner, Schulz and colleagues ${ }^{14}$ prepared silicon carbonyl complex $[\mathrm{L}(\mathrm{Br}) \mathrm{Ga}]_{2} \mathrm{Si}-\mathrm{CO}(\mathrm{L}=\mathrm{HC}[\mathrm{C}$ $\left.\left.(\mathrm{Me}) \mathrm{N}\left(2,6-{ }^{i} \mathrm{Pr}_{2}-\mathrm{C}_{6} \mathrm{H}_{3}\right)\right]_{2}\right)$ (7) bearing a gallium-based ligand framework, as orange crystals in $75 \%$ yield, by the reaction of $\mathrm{GaL}$ with $\mathrm{SiBr}_{4}$ under a $\mathrm{CO}$ atmosphere (Fig. 2a). Shortly after, our group succeeded in the synthesis and isolation of the silylsubstituted silicon carbonyl complex, $\left[\left(\mathrm{Me}_{3} \mathrm{Si}\right)_{3} \mathrm{Si}\right]\left({ }^{t} \mathrm{Bu}_{3} \mathrm{Si}\right) \mathrm{Si}-\mathrm{CO}$ (10), which is stable at ambient temperature ${ }^{15}$. Complex 10 was obtained as purple crystals in $90 \%$ yield on exposure of an equilibrium mixture of tetrasilyldisilene (8) and bis(silyl)silylene (9) to CO. Alternatively, the reaction of $4-N, N$-dimethylaminopyridine-stabilized bis(silyl)silylene (11) with $\mathrm{CO}$ also afforded 10. Furthermore, complex 10 can photolytically decarbonylate to generate an equilibrium mixture of 8 and $\mathbf{9}$. Both complexes 7 and 10 show remarkably stability both in the solid state $\left(T_{\mathrm{d}}=\right.$ $176-177^{\circ} \mathrm{C}$ for $7,76-77^{\circ} \mathrm{C}$ for 10 ) and in solution. Our group investigated that the silicon carbonyl complex $\left({ }^{t} \mathrm{Bu}_{3} \mathrm{Si}\right)_{2} \mathrm{Si}-\mathrm{CO}$ could also be obtained by the reaction of $\left({ }^{t} \mathrm{Bu}_{3} \mathrm{Si}_{2}\right)_{2} \mathrm{SiBr}_{2}$ and potassium graphite $\left(\mathrm{KC}_{8}\right)$ in a $\mathrm{CO}$ atmosphere, whereas acyclic imino(silyl)- and imino(siloxy)silylenes showed no reaction towards $\mathrm{CO}$.

Further insight regarding the chemical bonding in the silicon carbonyl complexes was gained by nuclear magnetic resonance (NMR) and infrared (IR) spectroscopy. Complexes 7 and $\mathbf{1 0}$ show a downfield signal for CO in the ${ }^{13} \mathrm{C}$ NMR spectrum and an enormous upfield signal for the Si-CO moiety in the ${ }^{29} \mathrm{Si} \mathrm{NMR}$ spectrum; notably, a red shift for the CO band was observed in IR spectroscopy. These results indicate a significantly stronger donor-acceptor interaction on the Si-CO moiety. Both complexes 7 and $\mathbf{1 0}$ bear electropositive groups (gallyl group for 7, silyl groups for 10), which have strong $\sigma$-donating properties (Fig. 2b). The polarization of the Si-CO moiety and the electron density at the silicon center are increased by the effect of these electropositive ligands, which induces $\pi$-backdonation from the silylene centers to the $\mathrm{CO}$ ligands. Their analytical data together with theoretical studies revealed that complexes 7 and 10 exhibit

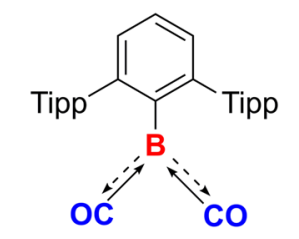

Tipp $=\mathrm{C}_{6} \mathrm{H}_{2}-2,4,6-{ }^{-} \mathrm{Pr}_{3}$ 1

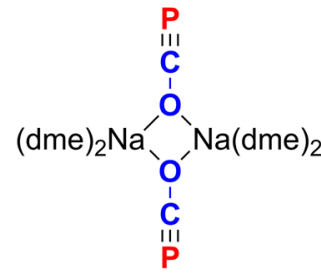

2

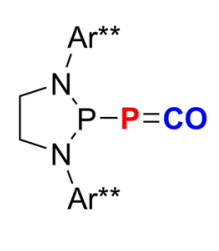

3
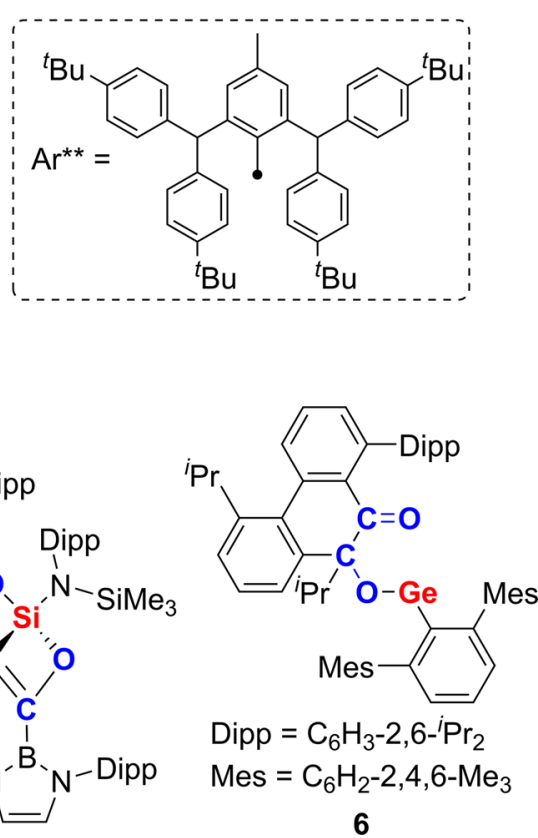

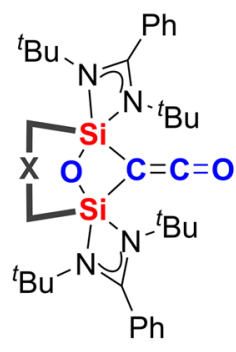
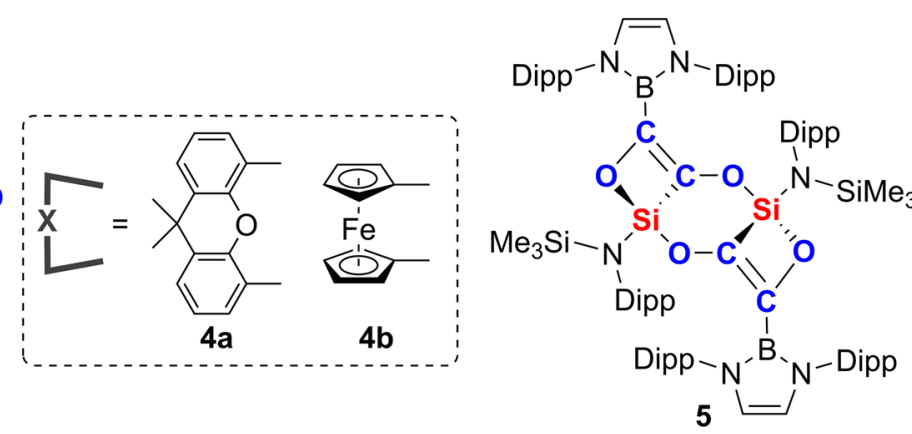

Fig. 1 Selected examples of main-group element compounds formed in the reactions with CO. Boron dicarbonyl complex (1) $)^{5}$, sodium phosphacyanate $(\mathbf{2})^{7}$, phosphino-phosphaketene $(\mathbf{3})^{8}$, and reductive homologation products $(\mathbf{4 - 6})^{11-13}$. 
a)

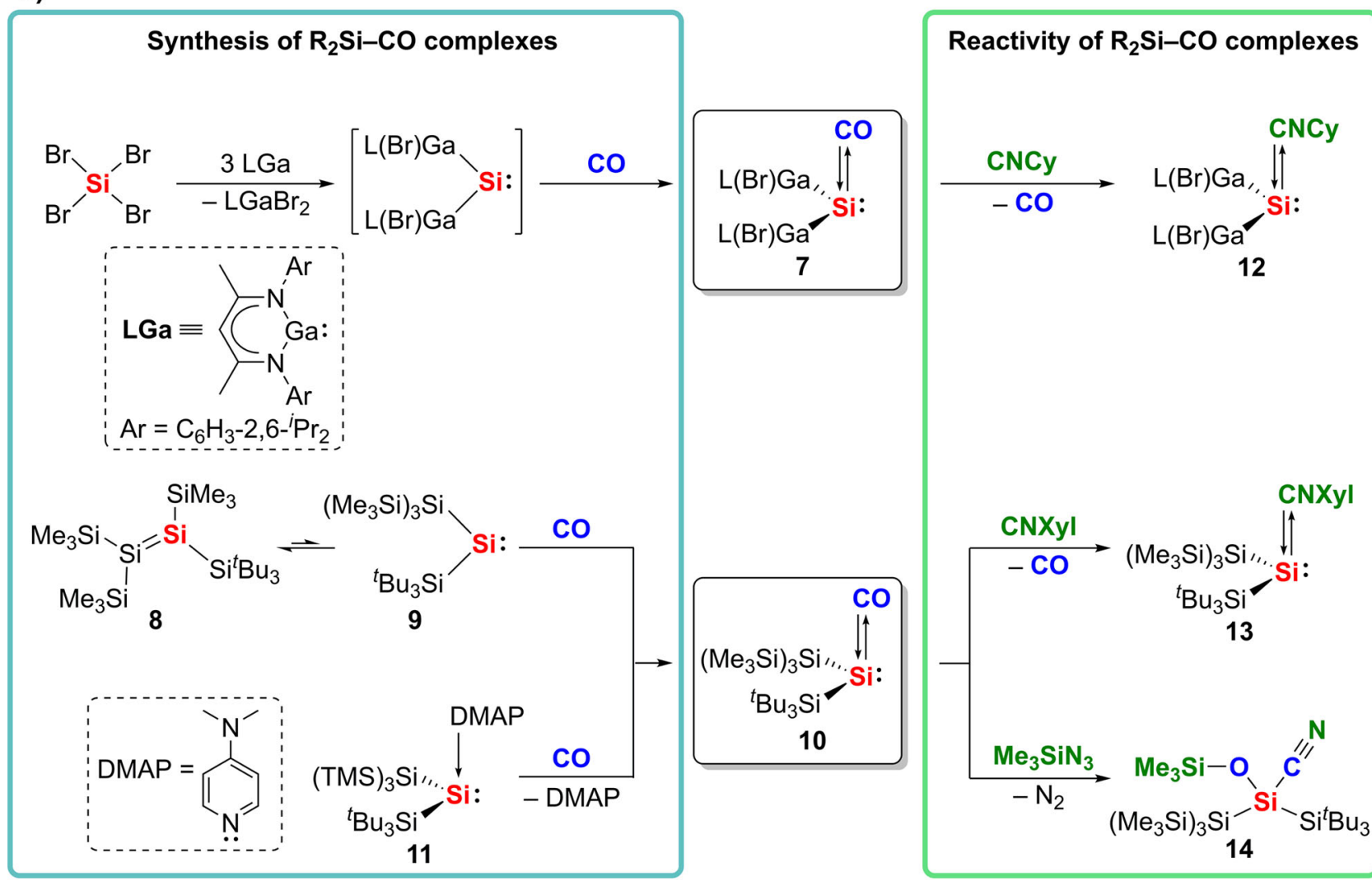

b) empty $p$ orbital

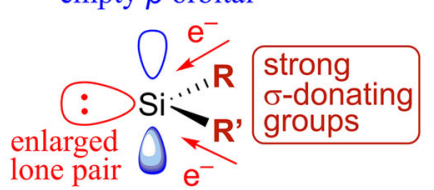

c) empty $\pi^{*}$ orbital

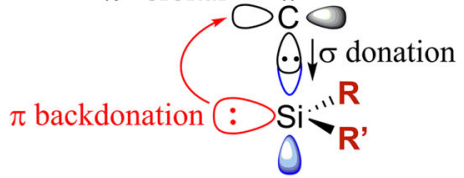

7: R/R' = Ga(Br)L

10: $R=\operatorname{Si}\left(\mathrm{SiMe}_{3}\right)_{3}, \mathrm{R}^{\prime}=\mathrm{Si}^{\mathrm{t} B u_{3}}$ d)
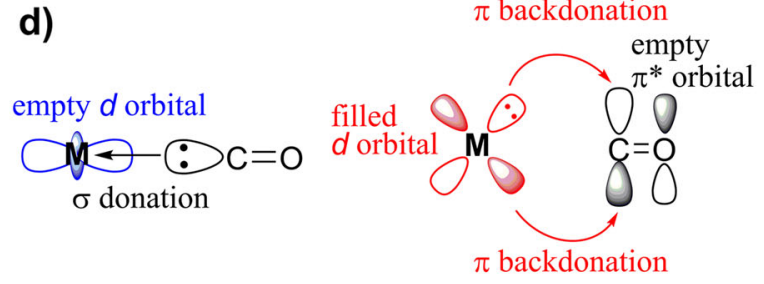

Fig. 2 Silicon carbonyl complexes. Synthesis of silicon carbonyl complexes ( $\mathbf{7}$ and $\mathbf{1 0}$ ) and their reactivity (a). Important molecular orbitals in silylenes bearing electropositive groups (b) and the frontier orbital interactions in silicon carbonyl complexes (c). Frontier orbital interactions in transition-metal (M) carbonyl complexes (d). CNCy, cyclohexyl isocyanide; CNXyl, 2,6-dimethylphenyl isocyanide.

strong donor-acceptor CO-Si bonding, with $\mathrm{CO} \rightarrow \mathrm{Si} \sigma$ donation and $\mathrm{Si} \rightarrow \mathrm{CO} \pi$-backdonation, which is evocative of TM carbonyl complexes (Fig. 2c, d).

The successful isolation of silicon carbonyl complexes has also led to an investigation of their reactivity. Complexes 7 and 10 exhibit a ligand exchange reaction, which is archetypal for TM carbonyl complexes. Silylene isocyanide complexes [L(Br) $\mathrm{Ga}]_{2} \mathrm{Si}-\mathrm{CNCy}(12)$ and $\left[\left(\mathrm{Me}_{3} \mathrm{Si}\right)_{3} \mathrm{Si}\right]\left({ }^{t} \mathrm{Bu}_{3} \mathrm{Si}\right) \mathrm{Si}-\mathrm{CNXyl}$ (13) were obtained by the reactions of 7 and $\mathbf{1 0}$ with isocyanides $(\mathrm{R}-\mathrm{CN})$, respectively. The stronger $\sigma$-donation of the isocyanides, compared to that of $\mathrm{CO}$, should be the driving force. In addition, complex $\mathbf{1 0}$ shows a functionalization reaction of the $\mathrm{CO}$ moiety, which is also a prototypical reaction for TM carbonyl complexes. The reaction of $\mathbf{1 0}$ with trimethylsilyl azide $\left(\mathrm{Me}_{3} \mathrm{SiN}_{3}\right)$ afforded the silyl cyanide $\left[\left(\mathrm{Me}_{3} \mathrm{Si}\right)_{3} \mathrm{Si}\right]\left({ }^{t} \mathrm{Bu}_{3} \mathrm{Si}\right)$ $\mathrm{Si}\left(\mathrm{OSiMe}_{3}\right)(\mathrm{CN})$ (14). Thus, complexes 7 and 10 show reactivity as TM mimics.

\section{Outlook}

Thanks to the enormous recent progresses in main-group chemistry, several main-group element carbonyl complexes including the silicon analogs were isolated as stable compounds and their structural motif and chemical behavior has come to light. However, the isolable carbonyl complexes of many $p$-block elements such as heavier Group 13 elements including aluminium, the third most abundant element, are still missing. The heavier Group 14 analogs, germanium and tin carbonyl complexes $\mathrm{R}_{2} \mathrm{E}-\mathrm{CO}(\mathrm{E}=\mathrm{Ge}, \mathrm{Sn})$, have also not been reported but could be candidates for application in catalytic cycles. Contrary to the case of silicon, the divalent states in germanium and tin species are relatively stable, which may induce a migratory insertion of the coordinated $\mathrm{CO}$ in the germanium/tin carbonyl complexes. These complexes may provide viable catalysts instead of TM complexes for important catalytic reactions in industrial applications. To isolate these carbonyl complexes as stable 
compounds, appropriate molecular design is required. Given the success in the synthesis of the silicon carbonyl complexes $[\mathrm{L}(\mathrm{Br})$ $\mathrm{Ga}]_{2} \mathrm{Si}-\mathrm{CO} 7$ and $\left[\left(\mathrm{Me}_{3} \mathrm{Si}\right)_{3} \mathrm{Si}\right]\left({ }^{t} \mathrm{Bu}_{3} \mathrm{Si}\right) \mathrm{Si}-\mathrm{CO} \mathbf{1 0}$, the introduction of bulky electropositive groups such as silyl groups to the $\mathrm{Ge} / \mathrm{Sn}$ element center is effective to stabilize the corresponding carbonyl complexes. The bond energy of $\mathrm{E}-\mathrm{Si}$ (silyl group) $(\mathrm{E}=\mathrm{Ge}, \mathrm{Sn})$ bond in the potential complexes $\left(\mathrm{R}_{3} \mathrm{Si}\right)_{2} \mathrm{E}-\mathrm{CO}$ is weaker than when $\mathrm{E}=\mathrm{Si}\left(\mathrm{Si}-\mathrm{Si}: 327 \mathrm{~kJ} \mathrm{~mol}^{-1}\right.$, Si-Ge: $301 \mathrm{~kJ} \mathrm{~mol}^{-1}$ ), which also may be a driving force for a migratory insertion. Although TM complexes have been widely used as highly efficient catalysts for various important reactions, the development of TM free and eco-friendly systems have been underexplored. We believe that the ability of the main-group element carbonyl complexes may enable the widespread development of main-group element catalysis as alternatives to TMs and for new catalytic processes in the future.

Received: 8 October 2020; Accepted: 26 October 2020;

Published online: 23 November 2020

\section{References}

1. Peng, J.-B., Geng, H.-Q. \& Wu, X.-F. The chemistry of CO: carbonylation. Chem 5, 526-552 (2019).

2. Wu, X. et al. Observation of alkaline earth complexes $\mathrm{M}(\mathrm{CO})_{8}(\mathrm{M}=\mathrm{Ca}, \mathrm{Sr}$, or Ba) that mimic transition metals. Science 361, 912-916 (2018).

3. $\mathrm{Wu}, \mathrm{X}$. et al. Barium as honorary transition metal in action: experimental and theoretical study of $\mathrm{Ba}(\mathrm{CO})^{+}$and $\mathrm{Ba}(\mathrm{CO})^{-}$. Angew. Chem. Int. Ed. 57, 3974-3980 (2018).

4. Légaré, M.-A., Pranckevicius, C. \& Braunschweig, H. Metallomimetic chemistry of boron. Chem. Rev. 119, 8231-8261 (2019).

5. Braunschweig, $\mathrm{H}$. et al. Multiple complexation of $\mathrm{CO}$ and related ligands to a main-group element. Nature 522, 327-330 (2015).

6. Braunschweig, $\mathrm{H}$. et al. Main-group metallomimetics: transition metal-like photolytic CO substitution at boron. J. Am. Chem. Soc. 139, 1802-1805 (2017).

7. Puschmann, F. F. et al. Phosphination of carbon monoxide: a simple synthesis of sodium phosphaethynolate (NaOCP). Angew. Chem. Int. Ed. 50, 8420-8423 (2011).

8. Liu, L., Ruiz, D. A., Munz, D. \& Bertrand, G. A singlet phosphinidene stable at room temperature. Chem 1, 147-153 (2016).

9. Lavallo, V., Canac, Y., Donnadieu, B., Schoeller, W. W. \& Bertrand, G. CO fixation to stable acyclic and cyclic alkyl amino carbenes: stable amino ketenes with a small HOMO-LUMO gap. Angew. Chem. Int. Ed. 45, 3488-3491 (2006).

10. Kong, R. Y. \& Crimmin, M. R. Cooperative strategies for CO homologation. Dalton Trans. https://doi.org/10.1039/d0dt01564d (2020).
11. Wang, Y. et al. Silicon-mediated selective homo- and heterocoupling of carbon monoxide. J. Am. Chem. Soc. 141, 626-634 (2019).

12. Protchenko, A. V. et al. Reduction of carbon oxides by an acyclic silylene: reductive coupling of CO. Angew. Chem. Int. Ed. 58, 1808-1812 (2019).

13. Wang, X. et al. Room-temperature reaction of carbon monoxide with a stable diarylgermylene. J. Am. Chem. Soc. 131, 6912-6913 (2009).

14. Ganesamoorthy, C. et al. A silicon-carbonyl complex stable at room temperature. Nat. Chem. 12, 608-614 (2020).

15. Reiter, D. et al. Silylated silicon-carbonyl complexes as mimics of ubiquitous transition-metal carbonyls. Nat. Chem. https://doi.org/10.1038/s41557-02000555-4 (2020).

\section{Acknowledgements}

This project has received funding from the European Union's Horizon 2020 research and innovation programme under the Marie Skłodowska-Curie grant agreement No 754462 (Fellowship S.F.), as well as the WACKER Chemie AG and the European Research Council (SILION 637394).

\section{Author contributions}

S.F. and S.I. contributed to the writing and preparation of this manuscript.

\section{Competing interests}

The authors declare no competing interests.

\section{Additional information}

Correspondence and requests for materials should be addressed to S.I.

Reprints and permission information is available at http://www.nature.com/reprints

Publisher's note Springer Nature remains neutral with regard to jurisdictional claims in published maps and institutional affiliations.

\footnotetext{
Open Access This article is licensed under a Creative Commons Attribution 4.0 International License, which permits use, sharing, adaptation, distribution and reproduction in any medium or format, as long as you give appropriate credit to the original author(s) and the source, provide a link to the Creative Commons license, and indicate if changes were made. The images or other third party material in this article are included in the article's Creative Commons license, unless indicated otherwise in a credit line to the material. If material is not included in the article's Creative Commons license and your intended use is not permitted by statutory regulation or exceeds the permitted use, you will need to obtain permission directly from the copyright holder. To view a copy of this license, visit http://creativecommons.org/ licenses/by/4.0/
}

(c) The Author(s) 2020 